\title{
Effect of Various Compounding Methods on Acid Red 18050- Melamine Modified Urea Formaldehyde Resin Compound as Wood Modifier
}

\author{
Yuan Shi, ${ }^{\mathrm{a}, \mathrm{b}}$ Wenhua Lyu, ${ }^{\mathrm{a}, \mathrm{b}} *$ Xueyu Wang, ${ }^{\mathrm{b}}$ and Qiangqiang Liu ${ }^{\mathrm{b}}$
}

In order to simultaneously improve the strength and decoration properties of plantation wood, a multi-effect modifier was prepared by compounding acid red 18050(G) with melamine-modified urea formaldehyde resin (MUF). Various compounding methods for MUF synthesis such as adding dye with the first part urea $\left(U_{1 G}\right)$ or with the second part urea $\left(U_{2 G}\right)$, or direct blending with MUF resin $\left(\mathrm{B}_{\mathrm{G}}\right)$ were tested. Chinese fir plantation wood was impregnated with these modifiers separately, and its color, color fastness, and dyeing mechanism were studied. The results showed that $G$ had good compatibility with MUF and could prolong its storage time, and all compound modifiers exhibited permeability and coloring effect on Chinese fir wood. Compared with G-dyed wood under the same conditions, all the compound dyed wood had better color fastness to water, and the $U_{2 G}$-dyed was the best, the color fastness to xenon light of $U_{2 G}$ dyed wood was greatly improved.. Fourier transform infra-red (FTIR) analysis showed that compared with MUF-modified wood, the dye affected MUF hydroxyl-methylation reaction in $U_{1 G}$, lowered the polycondensation degree, and extended its storage time. The dye might have promoted the ionic reaction between resin amino and dye sulfonic groups in $\mathrm{U}_{2 \mathrm{G}}$, thus displaying better color fastness.

Keywords: MUF resin; Acid red 18050; Compounding method; Color fastness; FTIR

Contact information: a: Research Institute of Forestry New Technology, Chinese Academy of Forestry, Beijing 100091, China; b: Research Institute of Wood Industry, Chinese Academy of Forestry, Beijing 100091, China; *Corresponding author:lwh_lily@163.com

\section{INTRODUCTION}

Wood has many unique properties and characteristics, and it is a natural and renewable resource. With the increasing consumption of wood, the global natural forest wood is increasingly depleted, and it is imperative to enhance the efficient utilization of plantation wood especially in China (Chen et al. 2014). Fast-growing plantation wood exhibits low density, low strength, unstable dimensions, and poor decoration. Such attributes are usually associated with the manufacture of low-value products. The combination of wood functional modification and wood dyeing could improve wood physical, mechanical, and decorative properties simultaneously, thus enhancing its efficient utilization (Zhang et al. 2013; Xu et al. 2017). Resin impregnation is an effective way to improve wood's physical and mechanical properties (Yue et al. 2016; Altun and Tokdemir 2017; Li et al. 2018). In recent years, melamine-modified urea formaldehyde (MUF) resin had been widely used in wood modification because of its excellent performance and low cost. The density, bending strength, compressive strength, and fire resistance, and other properties of plantation poplar wood have been improved through 
MUF impregnation. Due to their wide availability, low price, good permeability, and good chemical stability, acid dyes were the first choice for wood dyeing. Li et al. (2011) studied the dyeing properties of acid dyes on various tree species. Among the commonly used water-soluble dyes, the dyes with good permeability exhibit little binding force, low leaching resistance, and poor light fastness. Wang et al. (2016) improved the water leaching resistance and light stability of acid dyes using chitosan treatment. A previous study by the authors had shown that the acid dyes had minor effects on the reinforcement function of MUF resin ( $\mathrm{Xu}$ et al. 2017). The wood resin impregnation and dyeing modification not only greatly simplify the dyeing process, but they also improve dye color fastness by resin's embedding and curing (Zheng et al. 2016). In this study, acid red G was compounded with MUF resin through three ways, i.e., adding it with the first urea or with the second urea during MUF synthesis, or directly blending it with prepared MUF. The effects of various compounding methods on its color, color fastness, and dyeing mechanism on wood were explored.

\section{EXPERIMENTAL}

\section{Materials}

Chinese fir (Cunninghamia lanceolata) plantation wood was collected from Jiangxi province in China. Its moisture content was modulated to about $12 \%$, and air-dry density was about $0.332 \mathrm{~g} / \mathrm{cm}^{3}$. The dimensions of the samples were $60 \mathrm{~mm}(L) \times 30 \mathrm{~mm}(R) \times 5$ $\mathrm{mm}(T)$. The reagents was provided by Shanghai Aladdin Bio-Chem Technology Co. Ltd. (Shanghai, China), including melamine $\left(\mathrm{C}_{3} \mathrm{H}_{6} \mathrm{~N}_{6}\right.$, CAS 108-78-1), methanol $\left(\mathrm{CH}_{4} \mathrm{O}\right.$, CAS 67-56-1), formaldehyde ( $\mathrm{CH}_{2} \mathrm{O}$, CAS 50-00-0), and urea $\left(\mathrm{CH}_{4} \mathrm{~N}_{2} \mathrm{O}\right.$, CAS 57-13-6). The mole ratio of melamine/methanol/formaldehyde/urea to synthetic MUF resin was 1/2.3/2.3/1.2. Acid Red 18050 (Common name acid red G, Molecular formula $\mathrm{C}_{18} \mathrm{H}_{13} \mathrm{~N}_{3} \mathrm{Na}_{2} \mathrm{O}_{8} \mathrm{~S}_{2}$, Molecular mass 509.42, Color Index 18050, CAS Number 3734-67-6) was provided by Guangchun Dyestuff Co. Ltd. (Beijing, China).

\section{Methods}

Experimental design

Acid red $18050(\mathrm{G})$ was added with the first part urea or with the second part urea (The first part urea and the second part urea means different portions of urea) during MUF resin synthetic process, or was directly blended with MUF in order to prepare the strengthening-dyeing modifier. White filter paper and Chinese fir plantation wood were both treated with the prepared compound modifiers. The dyeing properties and color fastness were studied and compared with $G$ water solution. The effects of three compounding methods on dye coloring performance of wood were evaluated, and its dyeing mechanism was analyzed via Fourier infra-red (FTIR) analysis.

\section{MUF resin synthesis}

First, formaldehyde (1660 g) and melamine (1270 g) were added into a reactor, the $\mathrm{pH}$ value of the reaction mixture was adjusted to 9, and then the mixture was heated to 70 ${ }^{\circ} \mathrm{C}$ for $1 \mathrm{~h}$. Second, methanol $(800 \mathrm{~g})$ and the first part of urea $\left(\mathrm{U}_{1}\right)(510 \mathrm{~g})$ were added, and allowed to react at $80{ }^{\circ} \mathrm{C}$ at $\mathrm{pH} 11$ for $0.5 \mathrm{~h}$. Third, the $\mathrm{pH}$ value was adjusted to 9.2 , and the second part of urea $\left(\mathrm{U}_{2}\right)(100 \mathrm{~g})$ was slowly added and allowed to react at $65{ }^{\circ} \mathrm{C}$ for $10 \mathrm{~min}$. Later, the $\mathrm{pH}$ value was again adjusted to about 7.5, and the reactant to water- 
soluble ratio was monitored every 5 min until it reached to 10 . The reaction mixture was cooled rapidly to obtain the modified MUF resin. Then its $\mathrm{pH}$ value, solids content, viscosity, stability, and color were measured, and the statistical averages of three replicates were calculated.

\section{Preparation of MUF-dye compound modifiers}

Based on previous study (Zheng et al. 2016), the mass percent of acid red 18050 used was selected as $1 \%$. The dye was added with $\mathrm{U}_{1}$ or $\mathrm{U}_{2}$ during MUF synthesis, or was directly blended with the prepared MUF, and the resulting compound was accordingly named as $\mathrm{U}_{1 \mathrm{G}}, \mathrm{U}_{2 \mathrm{G}}$ or $\mathrm{B}_{\mathrm{G}}$ modifier. The mass percent of each modifier was adjusted to $25 \%$ before wood impregnation.

\section{Resin properties test}

Resin viscosity was tested with NDJ-5S digital viscometer (Shanghai Ande Instrument and Equipment Co. Ltd., Shanghai, China). Its $\mathrm{pH}$ value was regulated with $10 \%$ (mass percent) with sodium hydroxide or hydrochloric acid solution, and tested by PHS-2F acidometer (Shanghai INESA Scientific Instrument Co., Ltd., Shanghai, China). Its solid content was determined as the mass retention percentage after it was oven-dried at $120^{\circ} \mathrm{C}$ for $2 \mathrm{~h}$.

\section{Wood impregnation treatment}

First, the wood samples were oven-dried and placed into an impregnation chamber. Second, the chamber was evacuated to $-0.09 \mathrm{MPa}$ for $0.5 \mathrm{~h}$. Third, the modifier was introduced into the chamber and the vacuum was removed. Thereafter, a positive pressure of about 1.0 MPa was maintained for $4 \mathrm{~h}$. Then the samples were taken out, air-dried to about $50 \%$ moisture content, and oven-dried to a constant weight with gradually increasing temperature up to $103^{\circ} \mathrm{C}$.

\section{Color measurement}

According to the CIE $1976 L^{*} a^{*} b^{*}$ color system, the lightness $\left(L^{*}\right)$, green-to-red $\left(a^{*}\right)$ and blue-to-yellow $\left(b^{*}\right)$ color indexes were measured using chromatic aberration meter (CR-400, Japan) under $\mathrm{D}_{65}$ light source, with vertical illumination and diffuse reflection. Color differences were calculated according to the formulas: $\Delta L^{*}=L_{1}{ }^{*}-L_{0}{ }^{*} ; \Delta a^{*}=a_{1}{ }^{*}-a_{0}{ }^{*}$; $\Delta b^{*}=b_{1}{ }^{*}-b_{0}{ }^{*} ; \Delta C^{*}($ color saturation difference $)=\left[\left(\Delta a^{*}\right)^{2}+\left(\Delta b^{*}\right)^{2}\right]^{1 / 2}$; and $\Delta E^{*}$ (total color difference) $=\left[\left(\Delta L^{*}\right)^{2}+\left(\Delta a^{*}\right)^{2}+\left(\Delta \underline{b}^{*}\right)^{2}\right]^{1 / 2}$. Circular filter papers $\left(60 \mathrm{~cm}\right.$ diameter, $L^{*}=95.69$, $a^{*}=0.48, b^{*}=3.65$ ) were each divided into four parts, and soaked in $\mathrm{U}_{1 \mathrm{G}}, \mathrm{U}_{2 \mathrm{G}}, \mathrm{B}_{\mathrm{G}}$, and $\mathrm{G}$ solutions for $20 \mathrm{~s}$, respectively, and then air-dried. Each sample color was measured through its three surface points, and the statistical averages of five repeat measurements were calculated.

\section{Wood color fastness}

Wood color fastness to water was represented by its color fading after being soaked in $500 \mathrm{~mL}$ of boiling water for $3 \mathrm{~h}$. Its color fastness to light was tested by xenon aging instrument (Xenotest Alpha+, USA) under the conditions: $42 \mathrm{w} / \mathrm{m}^{2}$ irradiation intensity, at $65{ }^{\circ} \mathrm{C}$ blackboard temperature, and $60 \%$ humidity. When the samples were irradiated for 0 h, 1 h, $2 \mathrm{~h}, 5 \mathrm{~h}, 7 \mathrm{~h}, 10 \mathrm{~h}, 25 \mathrm{~h}, 50 \mathrm{~h}, 75 \mathrm{~h}$, and $100 \mathrm{~h}$, the color was measured and their color differences were calculated. The statistical averages of three repeat samples were taken. 


\section{FTIR analysis}

The FTIR spectra were obtained from KBr pellets on Magna-IR 750 (Nicolet, USA). The scanning range used was from $4000 \mathrm{~cm}^{-1}$ to $400 \mathrm{~cm}^{-1}$, with $4 \mathrm{~cm}^{-1}$ resolution with 32 times repetition.

\section{RESULTS AND DISCUSSION}

\section{Solution Properties of Compound Modifiers}

Resin viscosity and resin solid content are two important properties. The viscosity represents its fluidity and permeability, and the solid content illustrates its final mechanical properties. As shown in Table 1, the MUF resin used for wood impregnation in this study was of low viscosity and it displayed a long storage period. No matter which compounding way was used, the dye had little effect on MUF solid content, viscosity, and $\mathrm{pH}$ value, and it likely would prolong the MUF storage time. The $U_{1 G}$ solution exhibited the best storage stability. Compared with MUF resin, $\mathrm{U}_{1 \mathrm{G}}$ solution had smaller solid content and lower $\mathrm{pH}$ value, and the $\mathrm{U}_{2 \mathrm{G}}$ solution had bigger solid content, and almost the same $\mathrm{pH}$ value. The $\mathrm{pH}$ values of MUF and G solution were about 8.53 and 8.40, respectively. This consistent alkalinity might be one of the reasons for their good compatibility.

\begin{tabular}{ccccc}
\multicolumn{5}{c}{ Table 1. Solution Properties of MUF Resin and Its Compound Dyes } \\
\hline \multirow{2}{*}{ Modifier } & $\begin{array}{c}\text { Solid Content } \\
(\%)\end{array}$ & $\begin{array}{c}\text { Viscosity } \\
(\mathrm{mPa} \cdot \mathrm{s})\end{array}$ & pH Value & $\begin{array}{c}\text { Storage Life } \\
(\mathrm{d})\end{array}$ \\
\hline \multirow{2}{*}{ MUF } & 54.3 & 5.7 & 8.53 & 25 \\
& $(0.02)^{\mathrm{a}}$ & $(0.11)$ & $(0.02)$ & $(0.04)$ \\
$\mathrm{U}_{1 G}$ & 53.1 & 5.8 & 8.34 & 40 \\
& $(0.03)$ & $(0.09)$ & $(0.02)$ & $(0.02)$ \\
$\mathrm{U}_{2 G}$ & 54.7 & 5.6 & 8.55 & 30 \\
& $(0.03)$ & $(0.15)$ & $(0.02)$ & $(0.03)$ \\
$\mathrm{BG}_{\mathrm{G}}$ & 55.0 & 5.9 & 8.66 & 30 \\
& $(0.02)$ & $(0.06)$ & $(0.02)$ & $(0.03)$ \\
\hline
\end{tabular}

a The number in parentheses represent the coefficient of variation.

As the $\mathrm{pH}$ values of compound dyes were different, the addition of dye at various stages might have different effects on MUF molecules. Since the sulfonic acid groups in Acid Red 18050 could interact with amino groups of MUF resin to form salt, the $U_{1}$-dye might hinder the addition reaction of resin molecules and thus partly affect the production of hydroxymethyl urea, which results in a lower $\mathrm{pH}$ value and smaller solid content (Wang et al. 2016). As the polycondensation reaction of MUF molecules occurred mainly between its hydroxymethyl compounds or between its hydroxymethyl groups $\left(-\mathrm{CH}_{2} \mathrm{OH}\right)$ and active hydrogen of amino groups $\left(-\mathrm{NH}_{2}\right)$, the $\mathrm{U}_{2}$-dye might reduce the content of free formaldehyde molecules, thus reducing the proportion of small molecular resin and increasing the crosslinking degree of resin molecules. This could cause a higher solid content (Rizk et al. 2015). Thus, the dye when added with $U_{1}$ and $U_{2}$ urea during MUF synthesis might have certain impact on MUF synthetic reaction.

\section{Dyeing Performance}

Color changes of white filter paper and Chinese fir wood treated with MUF, G, $\mathrm{U}_{1 \mathrm{G}}, \mathrm{U}_{2 \mathrm{G}}$, or $\mathrm{B}_{\mathrm{G}}$ solutions are shown in Table 2. The color of MUF treated paper mainly 
showed a decrease in lightness $\left(L^{*}\right)$, and the paper dyed with $\mathrm{G}, \mathrm{U}_{1 \mathrm{G}}, \mathrm{U}_{2 \mathrm{G}}$ or $\mathrm{B}_{\mathrm{G}}$ all turned red obviously. Their $\Delta L^{*}$ was decreased, whereas $\Delta a^{*}$ and $\Delta b^{*}$ were increased. The $\Delta E^{*}$ values changed from large to small and were in order of $\mathrm{G}>\mathrm{B}_{\mathrm{G}}>\mathrm{U}_{1 \mathrm{G}}>\mathrm{U}_{2 \mathrm{G}}$. The G-dyed paper had the reddest hues. As for the compound dyed papers, $\mathrm{B}_{\mathrm{G}}$ was the reddest, $\mathrm{U}_{2 \mathrm{G}} \mathrm{Was}$ the least red, and $U_{1 G}$ was in between them. This indicated that the $U_{2}$-dye had a greater influence on the binding states of MUF chromophore and auxochrome groups (Moya et al. 2012).

Table 2. Dyeing Performance of MUF-Acid Red G Compound Modifiers

\begin{tabular}{c|ccccc|ccccc}
\hline \multirow{2}{*}{ Modifier } & \multicolumn{6}{|c|}{ Filter Paper } & \multicolumn{5}{c}{ Chinese Fir Wood } \\
& $\Delta L^{*}$ & $\Delta a^{*}$ & $\Delta b^{*}$ & $\Delta C^{*}$ & $\Delta E^{*}$ & $\Delta L^{*}$ & $\Delta a^{*}$ & $\Delta b^{*}$ & $\Delta C^{*}$ & $\Delta E^{*}$ \\
\hline \multirow{2}{*}{ MUF } & -9.40 & -0.32 & 1.43 & 1.40 & 9.51 & 0.08 & -0.50 & -0.36 & -0.47 & 0.62 \\
& $(0.11)^{\mathrm{a}}$ & $(2.63)$ & $(0.34)$ & $(0.64)$ & $(1.62)$ & $(1.78)$ & $(1.65)$ & $(3.17)$ & $(4.42)$ & $(5.53)$ \\
\multirow{3}{*}{$\mathrm{G}$} & -51.45 & 60.91 & 9.96 & 59.19 & 80.35 & -33.59 & 46.62 & -3.34 & 33.06 & 55.62 \\
& $(0.32)$ & $(0.05)$ & $(0.13)$ & $(0.06)$ & $(0.89)$ & $(5.28)$ & $(6.85)$ & $(4.74)$ & $(7.49)$ & $(7.88)$ \\
\multirow{3}{*}{$\mathrm{U}_{1 G}$} & -53.11 & 54.80 & 19.40 & 60.2 & 78.74 & -26.78 & 36.61 & -15.79 & 37.45 & 48.03 \\
& $(0.84)$ & $(1.57)$ & $(0.64)$ & $(1.68)$ & $(0.65)$ & $(8.20)$ & $(6.35)$ & $(7.11)$ & $(1.20)$ & $(7.25)$ \\
$\mathrm{U}_{2 G}$ & -52.36 & 48.61 & 18.01 & 56.21 & 73.68 & -29.48 & 33.68 & -12.16 & 40.02 & 46.38 \\
& $(0.58)$ & $(1.58)$ & $(1.40)$ & $(1.61)$ & $(1.36)$ & $(4.31)$ & $(2.06)$ & $(3.69)$ & $(2.97)$ & $(4.75)$ \\
$B_{G}$ & -50.02 & 58.02 & 22.01 & 49.98 & 79.70 & -29.14 & 37.98 & -10.79 & 35.68 & 49.07 \\
& $(0.83)$ & $(1.13)$ & $(0.34)$ & $(0.64)$ & $(1.65)$ & $(2.68)$ & $(5.79)$ & $(2.74)$ & $(3.43)$ & $(4.92)$ \\
\hline
\end{tabular}

a The number in parentheses represent the coefficient of variation.

Results of impregnating treatment showed that under the same conditions the weight ratios of MUF, $\mathrm{U}_{1 \mathrm{G}}, \mathrm{U}_{2 \mathrm{G}}$, and $\mathrm{B}_{\mathrm{G}}$ absorbed by Chinese fir wood reached to $281.1 \%$, $265.6 \%, 274.3 \%$, and $271.9 \%$, respectively. The addition of dye had only slight effect on the high permeability of low molecular weight MUF resin. According to the relations between wood density and strengths, the similar intake meant similar final strengths. This was consistent with previous research results, where the acid dyes had minor effects on the reinforcement function of MUF resin (Xu et al. 2017).

In Table 2, all $\Delta a^{*}$ values were increased greatly in the order of $\mathrm{G}>\mathrm{B}_{\mathrm{G}}>\mathrm{U}_{1 \mathrm{G}}>$ $\mathrm{U}_{2 \mathrm{G}}$. It was observed that the red color of G-dyed wood was darker but more uneven with color lumps. Among the compound dyed wood, $\mathrm{B}_{\mathrm{G}}$ had the biggest, and $\mathrm{U}_{2 \mathrm{G}}$ had the smallest $\Delta a^{*}$ value. This was in accordance with the dyeing results of filter paper. Color difference of 6.0 NBS to 12.0 NBS was very strong to naked eye (Lv et al. 2013). All $\Delta E^{*}$ values were above $46 \mathrm{NBS}$, and the dyed wood all turned red. But the $\Delta E^{*}$ difference of the compound dyed wood $\left(\mathrm{U}_{1 \mathrm{G}}, \mathrm{U}_{2 \mathrm{G}}\right.$, and $\left.\mathrm{B}_{\mathrm{G}}\right)$ was less than $3 \mathrm{NBS}$. All the compound modifiers showed good dyeability, and the coloring performance was almost the same except color saturation.

The $\Delta C^{*}$ value changed from small to large in order of $\mathrm{G}<\mathrm{B}_{\mathrm{G}}<\mathrm{U}_{1 \mathrm{G}}<\mathrm{U}_{2 \mathrm{G}}$. Compared with $\mathrm{G}$ dyed wood, the compound dyed wood had more saturated color, and the $\mathrm{U}_{2 \mathrm{G}}$-dyed wood color was the most saturated. Compounding $\mathrm{G}$ with MUF resin, especially adding it with $\mathrm{U}_{2}$ urea during MUF synthesis, could effectively improve its dyeing level and color saturation on Chinese fir wood. 


\section{Color Fastness to Water}

All the dyed wood was separately soaked in boiling water for $3 \mathrm{~h}$ to investigate the color degradation in water. As can be seen from Table 3, after water soaking test the $\Delta E^{*}$ values of $\mathrm{G}, \mathrm{U}_{1 \mathrm{G}}, \mathrm{U}_{2 \mathrm{G}}$, and $\mathrm{B}_{\mathrm{G}}$ dyed wood were 14.52, 6.81, 3.65, and $8.19 \mathrm{NBS}$ respectively, and all the wood faded. Acid red G was water soluble, and it was bonded to wood mainly by physical adsorption (Li et al. 2005); hence it was easily dissolved by water, and the $\mathrm{G}$ - dyed wood faded the most. By contrast, the $\Delta E^{*}$ of $\mathrm{U}_{1 \mathrm{G}}, \mathrm{U}_{2 \mathrm{G}}$, and $\mathrm{B}_{\mathrm{G}}$ dyed wood decreased by $26.6 \%, 71.9 \%$, and $16.6 \%$, respectively. Therefore, MUF could inhibit dye from being dissolved by water to some extent; especially the $U_{2}$ addition greatly improved the dye water resistance. The MUF resin cured in wood was not only partly chemically crosslinked with wood components, but it also combined with dye molecules to produce sulfonate via ionic bonding. Thus, the water dissolution of dye was inhibited (Lang et al. 2013; Wang et al. 2016). The inhibiting effect depended on the strength and quantity of ionic bonds formed between the resin and dye molecules. The water fastness of $U_{2 \mathrm{G}}$ dyed wood was the best, indicating that the cross-linking between its resin and dye molecules was relatively more stable.

Table 3. Color Change of the Modified Wood after Water Leaching Treatment

\begin{tabular}{cccccc}
\hline Modified Wood & $\Delta L^{*}$ & $\Delta a^{*}$ & $\Delta b^{*}$ & $\Delta C^{*}$ & $\Delta E^{*}$ \\
\hline \multirow{2}{*}{ Control } & -9.16 & 1.77 & 0.03 & 0.52 & 9.33 \\
& $(3.96)^{\mathrm{a}}$ & $(2.64)$ & $(4.21)$ & $(1.73)$ & $(2.51)$ \\
\multirow{2}{*}{ MUF } & 0.56 & 2.19 & 2.28 & 2.33 & 0.56 \\
& $(2.54)$ & $(1.55)$ & $(1.93)$ & $(2.02)$ & $(2.54)$ \\
$\mathrm{G}$ & 10.14 & -9.32 & -4.61 & -6.55 & 14.52 \\
& $(1.6)$ & $(2.38)$ & $(2.54)$ & $(2.29)$ & $(2.03)$ \\
$\mathrm{U}_{1 G}$ & 4.59 & -4.28 & 2.65 & -7.17 & 6.81 \\
& $(5.27)$ & $(4.72)$ & $(3.66)$ & $(8.71)$ & $(7.20)$ \\
$\mathrm{U}_{2 G}$ & 1.54 & -2.65 & 1.98 & -0.35 & 3.65 \\
& $(5.83)$ & $(6.10)$ & $(5.33)$ & $(5.06)$ & $(4.48)$ \\
$\mathrm{B}_{G}$ & 5.16 & -6.26 & 1.18 & -14.3 & 8.19 \\
& $(1.32)$ & $(1.78)$ & $(3.65)$ & $(1.34)$ & $(1.99)$ \\
\hline
\end{tabular}

a The number in parentheses represents the coefficient of variation.

\section{Color Fastness to Light}

Color change via the time required for $\mathrm{G}, \mathrm{U}_{1 \mathrm{G}}, \mathrm{U}_{2 \mathrm{G}}$, and $\mathrm{B}_{\mathrm{G}}$ dyed-wood irradiated with xenon light was studied to characterize their color light fastness. As depicted in Fig. 1 , all the dyed-wood faded with increasing irradiation time. Further, the $\Delta a^{*}$ value was decreased, and their $\Delta L^{*}$ and $\Delta b^{*}$ were increased with time. The color changed very rapidly within first $10 \mathrm{~h}$, then it gradually tended to be stable after $75 \mathrm{~h}$. When the irradiation time reached to about $35 \mathrm{~h}$, the discoloration of $\mathrm{B}_{\mathrm{G}}$-dyed wood began to exceed G-dyed wood. The light cleavage and aging of discoloring of MUF resin in wood began to aggravate wood discoloration (Hansmann et al. 2006). The $\Delta E^{*}$ of $\mathrm{G}, \mathrm{U}_{1 \mathrm{G}}, \mathrm{U}_{2 \mathrm{G}}$, and $\mathrm{B}_{\mathrm{G}}$ dyed wood irradiated with xenon light for $100 \mathrm{~h}$ were 21.11, 20.39, 13.14, and $23.38 \mathrm{NBS}$, respectively. The direct blending could not improve $\mathrm{G}$ light resistance, and the wood final light discoloration was more serious due to MUF light aging. Among the dyed-wood, $\mathrm{U}_{2 \mathrm{G}^{-}}$ dyed wood had the smallest $\Delta E^{*}$, which was reduced by $37.8 \%, 35.6 \%$, and $43.8 \%$, 
respectively compared with $\mathrm{G}, \mathrm{U}_{1 \mathrm{G}}$, and $\mathrm{B}_{\mathrm{G}}$ dyed wood. Adding $\mathrm{G}$ with $\mathrm{U}_{2}$ urea during MUF synthesis improved $G$ water resistance and light fastness. Since polycondensation could occur between resin hydroxymethyl groups and active hydrogen atoms of hydroxymethyl and amino groups, and also resin $-\mathrm{NH}_{2}$ and dye $-\mathrm{SO}_{3} \mathrm{H}$ could react to form sulfonate linkages by ionic binding, the chromophore, auxochrome groups, and crosslinking system of the $\mathrm{U}_{2 \mathrm{G}}-\mathrm{dyed}$ wood were more stable (Wang et al. 2016).

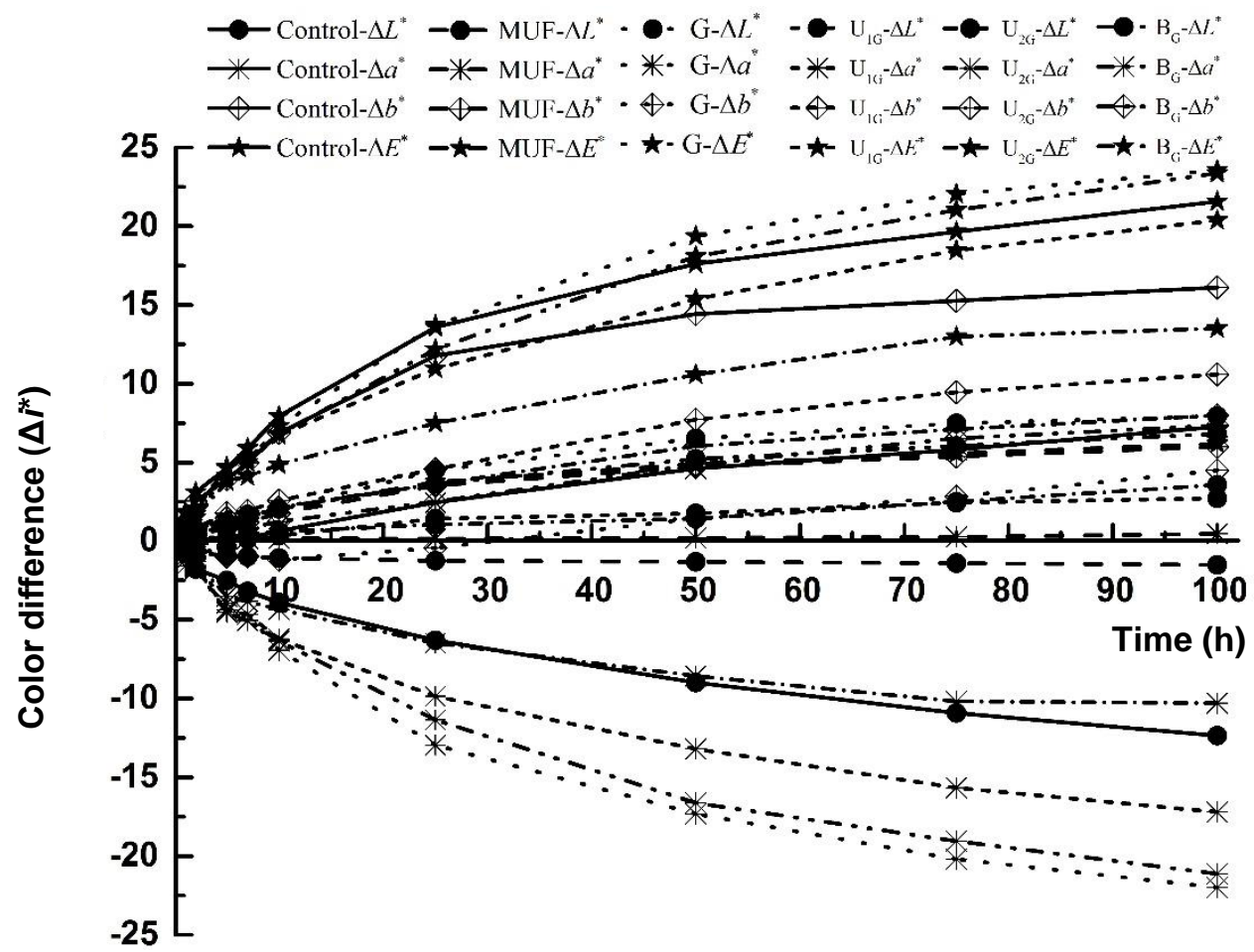

Fig. 1. Color change via time of various dyed wood irradiated with xenon light

\section{FTIR Analysis}

To further understand the bonding state of MUF, Acid Red 18050, and Chinese fir wood (Control), all wood modified with MUF, $\mathrm{G}, \mathrm{U}_{1 \mathrm{G}}, \mathrm{U}_{2 \mathrm{G}}$, or $\mathrm{B}_{\mathrm{G}}$ dyeing agents were analyzed by FTIR, as shown in Fig. 2. After wood being modified by MUF, the absorption peaks of hydroxyl group between $3300 \mathrm{~cm}^{-1}$ to $3500 \mathrm{~cm}^{-1}$ and that of amino group $(\mathrm{N}-\mathrm{C}=\mathrm{O})$ at $1658 \mathrm{~cm}^{-1}$ were intensified. The former was attributed to the interaction of resin $\mathrm{N}-\mathrm{H}$ and wood $-\mathrm{OH}$, and the latter was due to the reaction of resin pre-polymer $\left(-\mathrm{NHCH}_{2} \mathrm{OH}\right)$ and wood carbonyl $(\mathrm{C}=\mathrm{O})$ functional groups. Since part of wood hydroxyls were replaced by some active groups of MUF, the corresponding absorption peaks and intensities were changed. The MUF was reported to react with wood in two ways i.e., chemical bonding and physical filling (Lang et al. 2013; Chen et al. 2013). Basically, FTIR spectra of compound dyed-wood were consistent with MUF modified wood, as there were no new absorption peaks. Among the compound dyed wood, $\mathrm{U}_{1 \mathrm{G}}$ wood had the strongest absorption peak for $-\mathrm{CH}_{2} \mathrm{OH}$ at $1000 \mathrm{~cm}^{-1}, \mathrm{U}_{2 \mathrm{G}}$ wood had the weakest absorption peak of $\mathrm{N}-\mathrm{H}$ at $750 \mathrm{~cm}^{-1}$. The $\mathrm{U}_{1}$ dye might affect the production of hydroxymethyl urea, and reduce resin's final polycondensation degree, which could prolong its storage time. The $\mathrm{U}_{2}$ dye might promote the ionic bonding between resin $-\mathrm{NH}_{2}{ }^{+}$and dye $-\mathrm{SO}_{3} \mathrm{H}$ groups and result in its better water and light resistance (Tang et al. 2016) properties. 


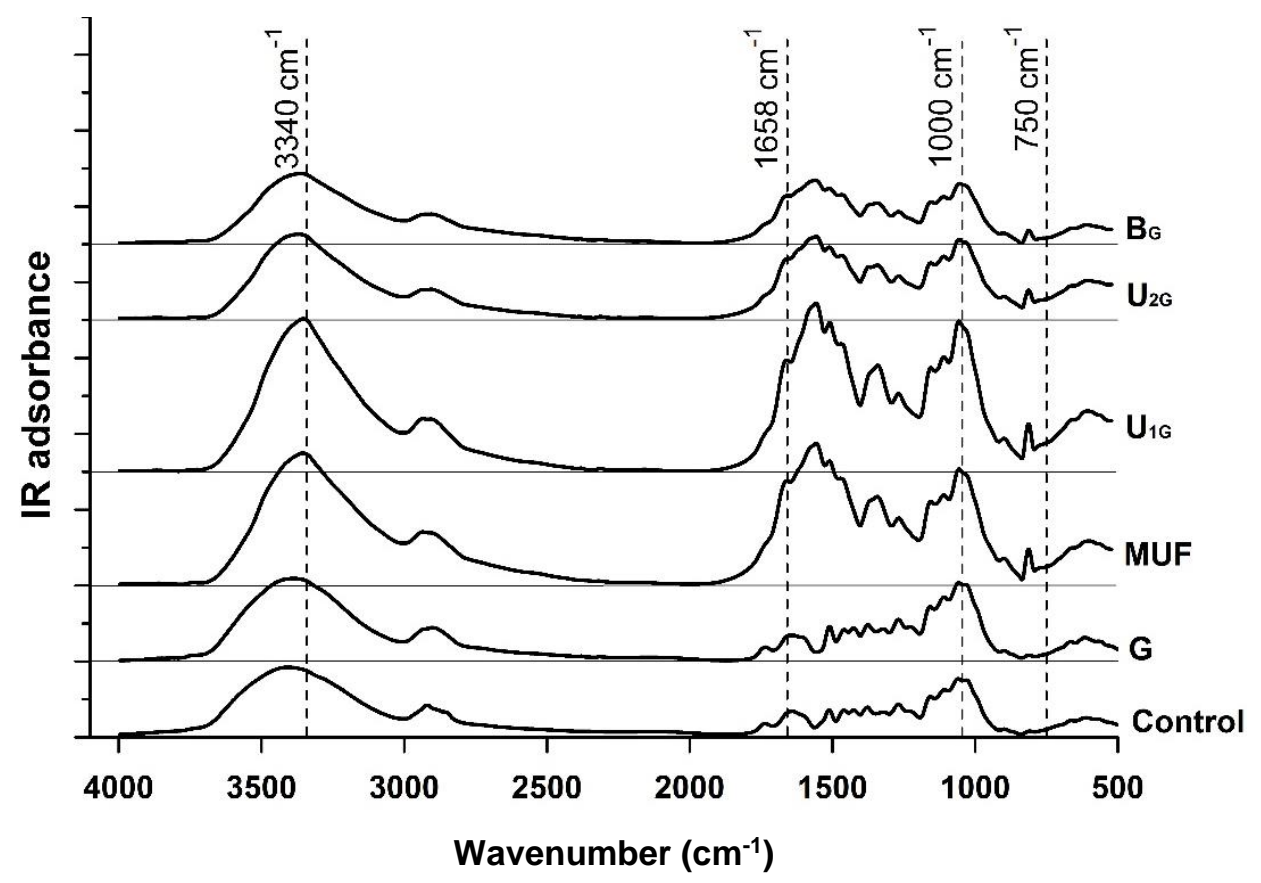

Fig. 2. FTIR spectra of the various dyed Chinese fir wood

\section{CONCLUSIONS}

1. Acid Red 18050 was added with $U_{1}$ urea or $U_{2}$ urea during MUF synthesis, or was directly blended with MUF to obtain $\mathrm{U}_{1 \mathrm{G}}, \mathrm{U}_{2 \mathrm{G}}$, and $\mathrm{B}_{\mathrm{G}}$ compound-dyeing agents. Results showed that no matter which compounding method was used, the miscibility of G and MUF was good, and G could prolong MUF storage time, especially when used with $\mathrm{U}_{1}$, while the solid content of $\mathrm{U}_{2 \mathrm{G}}$ solution was bigger. The dye has little effect on the high permeability of low molecular weight MUF resin for wood impregnation.

2. Compared with wood dyed in $\mathrm{G}$ water solution, $\mathrm{U}_{1 \mathrm{G}}, \mathrm{U}_{2 \mathrm{G}}$, and $\mathrm{B}_{\mathrm{G}}$ dyed-wood had more saturated and more homogenous color without any spots. As for three compoundmodified wood samples, there was no obvious difference in color, except that the color of $\mathrm{U}_{2 \mathrm{G}}$ dyed-wood was more saturated and its water and light resistance were better.

3. After being soaked in boiling water for $3 \mathrm{~h}$, the $\mathrm{U}_{1 \mathrm{G}}, \mathrm{U}_{2 \mathrm{G}}$, and $\mathrm{B}_{\mathrm{G}}$ dyed-wood had smaller $\Delta E^{*}$ than G-dyed wood, and it decreased by $26.6 \%, 71.9 \%$, and $16.6 \%$, respectively. Compared with $\mathrm{G}, \mathrm{U}_{1 \mathrm{G}}$, and $\mathrm{B}_{\mathrm{G}}$-dyed wood, the $\Delta E^{*}$ of $\mathrm{U}_{2 \mathrm{G}}$ dyed wood irradiated with xenon light for $100 \mathrm{~h}$ decreased by $37.8 \%, 35.6 \%$, and $43.8 \%$ respectively.

4. FTIR analysis showed that $\mathrm{U}_{1 \mathrm{G}}$-dyed wood had stronger absorption peak of $-\mathrm{CH}_{2} \mathrm{OH}$ at $1000 \mathrm{~cm}^{-1}$, and $\mathrm{U}_{2 \mathrm{G}}$-dyed wood had weaker absorption peak of $\mathrm{N}-\mathrm{H}$ at $750 \mathrm{~cm}^{-1}$. It was concluded that the polycondensation degree of $U_{1 \mathrm{G}}$ dyeing agent was lower and its storage time was longer. The resin and dye molecules of $U_{2 G}$ dyeing agent could form a more stable combination, which led to its better resistance to water and light. 


\section{ACKNOWLEDGMENTS}

This study was supported by the Fundamental Research Funds for Chinese Academy of Forestry Science (CAFYBB2018SZ013) and the National Science and Technology Program (No. 2015BAD14B01).

\section{REFERENCES CITED}

Altun, S., and Tokdemir, V. (2017). "Modification with melamine formaldehyde and melamine-urea formaldehyde resin to improve the physical and mechanical properties of wood," BioResources 12(1), 586-596. DOI: 10.15376/biores.12.1.586-596.

Chen, H., Lang, Q., Zhang, H., Wu, G., Zheng, X., and Pu, J. (2013). "Study of chemical modification by impregnation of fresh poplar log and by hot-press drying process," BioResources 8(3), 3924-3933. DOI: 10.15376/biores.8.3.3924-3933.

Chen, X. L., Ju, Q., and Lin, K. L. (2014). "Development status, issues and countermeasures of china's plantation," Wood Forestry Research 27(6), 54-59.

Hansmann, C., Deka, M., Wimmer, R., and Gindl, W. (2006). "Artificial weathering of wood surfaces modified by melamine formaldehyde resins," European Journal of Wood and Wood Products 64(3), 198-203. DOI: 10.1007/s00107-005-0047-y

Lang, Q., Chen, H. Y., and Pu, J. W. (2013). "Wood modification using a ureaformaldehyde prepolymer," Wood and Fiber Science 45(2), 162-169.

Li, H., Li, X. G., and Chen, W. M. (2011). "Study on dyeing properties of acid dyes for different tree species," Applied Mechanics and Materials 58-60, 205-208. DOI: 10.4028/AMM.58-60.205.

Li, H., and Yu, Z. M. (2005). "Combinative mechanism between dyestuff and wood," Journal of Beijing Forestry University 27(4), 78-81.

Li, J. J., Zhang, A. B., Zhang, S. F., and Gao, Q. (2018). "High-performance imitation precious wood from low-cost poplar wood via high-rate permeability of phenolic resins," Polymer Composites 39(7), 2431-2440. DOI: 10.1002/pc.24226.

Lv, W. H., Jiang, Z. H., Liu, X. E., and Liu, J. L. (2013). "Causes and removal of daemonorops margaritae cane's discoloration," Advanced Materials Research 634638, 909-912. DOI:10.4028/AMR.634-638.909

Moya, R., Soto, F. R., Jiménez, B. P., and Tenorio, C. (2012). "Relationship between wood color parameters measured by the CIELab system and extractive and phenol content in Acacia mangium and Vochysia guatemalensis from fast-growth plantations," Molecules 17(4), 3639-3652. DOI: 10.3390/molecules 17043639.

Rizk, H. F., Ibrahim, S. A., and EL-Borai, M. A. (2015). "Synthesis, fastness properties, color assessment and antimicrobial activity of some azo reactive dyes having pyrazole moiety," Dyes and Pigments 112, 86-92. DOI: 10.1016/j.dyepig.2014.06.026

Tang, R. L., Yu, Z. M., Zhang, Y., and Qi, C. (2016). "Synthesis, characterization, and properties of antibacterial dye based on chitosan," Cellulose 23(3), 1741-1749. DOI: 10.1007/s10570-016-0935-9.

Wang, X., Tang, R., Zhang, Y., Yu, Z., and Qi, C. (2016). "Preparation of a novel chitosan based biopolymer dye and application in wood dyeing," Polymers 8(9), 338. DOI: 10.3390/polym8090338. 
Xu, M. S., Lv, W. H., and Wang, X. Y. (2017). "Properties of strengthening-dyeingcombined modified plantation poplar wood," Scientia Silvae Sinicae 53(1), 82-87. DOI: 10.11707/j.1001-7488.20170110.

Yue, K., Liu, W. Q., Chen, Z. J., Lu, X. N., and Lu, W. D. (2016). "Investigation of the creep property of fast-growing poplar wood modified with low molecular weight resins," BioResources 11(1), 1620-1633. DOI: 10.15376/biores.11.1.1620-1633.

Zhang, M., Xu, Y., Wang, S. L. Shi, J. Y., Liu, C. Y., and Wang, C. Y. (2013). "Improvement of wood properties by composite of diatomite and 'phenol-melamineformaldehyde' co-condensed resin," Journal of Forestry Research 24(4), 741-746.

Zheng, Y. X., Lv, W. H., and Xu, M. S. (2016). "Color fastness to water of strengthening-dyeing-combined modified poplar wood," Journal of Northeast Forestry University 44(2), 39-41.

Article submitted: April 1, 2019; Peer review completed: August 9, 2019; Revised version received: September 22, 2019; Accepted: September 23, 2109; Published:

September 30, 2019.

DOI: 10.15376/biores.14.4.9100-9109 